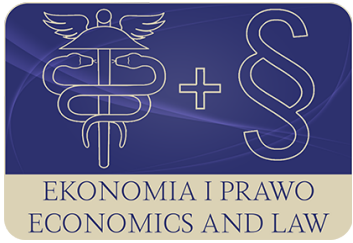

EKONOMIA I PRAWO. ECONOMICS AND LAW

Volume 17, Issue 1, March 2018

p-ISSN 1898-2255, e-ISSN 2392-1625

www.economicsandlaw.pl

ECONOMICS AND LAW

ORIGINAL ARTICLE

received 13.06.2017; revised 01.12.2017; accepted 31.03.2018

Citation: Cupiał, M., Szeląg-Sikora, A., Sikora, J., Rorat, J., \& Niemiec, M. (2018). Information technology tools in corporate knowledge management. Ekonomia i Prawo. Ecomomics and Law, 17(1):

5-15. doi:10.12775/EiP.2018.001.

\title{
Information technology tools in corporate knowledge management
}

\author{
MICHAE CUPIAE \\ corresponding author \\ University of Agriculture in Krakow, Faculty of Production and Power Engineering, ul. Balicka 116B, \\ 30-149 Krakow, Poland \\ $\square$ michal.cupial@ur.krakow.pl
}

ANNA SZELĄG-SIKORA

University of Agriculture in Krakow, Faculty of Production and Power Engineering, Poland

๑anna.szelag-sikora@ur.krakow.pl

\section{JAKUB SIKORA}

University of Agriculture in Krakow, Faculty of Production and Power Engineering, Poland

$\square$ jakub.sikora@ur.krakow.pl

\section{JOANNA RORAT}

University of Agriculture in Krakow, Faculty of Production and Power Engineering, Poland ๒ joannarorat@02.pl

\section{MARCIN NIEMIEC}

University of Agriculture in Krakow, Faculty of Agriculture and Economics, Poland

$\square$ marcin.niemiec@ur.krakow.pl

\begin{abstract}
Motivation: Knowledge management is currently one of the most important factors determining the company's market position. It depends not only on the skilful use of resources, but also on obtaining a synergistic effect. To manage knowledge, managers must possess not only the appropriate resources of knowledge, but also must have determined

management structure with the assistance of the IT (information technology) tools.

Aim: The purpose of the article was to present how the modern enterprise knowledge management process is supported by information technology. For this purpose, was sum-
\end{abstract}


marized selected indicators characterizing the use of ICT in various types of enterprises in the country. It assumed that it is important not only the equipment the companies with information technology tools, but also the degree of use of these tools.

Results: Usage of ICT in Poland reaches ratios much lower than the average for the European Union. Large differences in the use of information technology occurs in individual groups of companies. Larger companies have reached a much higher degree of saturation of IT tools than smaller objects. For example, the number of Polish enterprises with computers was $94.7 \%$, in the case of large companies it is $99.8 \%$. Even greater discrepancy relates to access to the Internet. You may also notice differences in each province. Introduction of modern technologies related to computer science and computers (eg. cloud computing, big data, social media, e-commerce etc) enables effective knowledge management in companies. The indicators show that the management team appreciates the im-

portance of knowledge and consistently invests for its development.

Keywords: knowledge management; information technology; IT; computer; internet users JEL: D83; L63; O31; Q19

\section{Introduction}

One of the most important tasks that enterprises face nowadays is the streamlining of business processes. This enables their effective development as well as implementation of innovations enabling introduction of new significant solutions, work methods and new services. This is only possible in enterprises of a high technological and organisational culture. Such opportunities are created by the knowledge-based economy that is dominated by products and services whose value emphatically depends on knowledge and not material resources.

In the modern economy, a process can be observed that involves gradual transition from the material-intensive businesses based on economies of scale to economies based on knowledge and modern technologies (Loshin, 2001, pp. 1-24; Siesfeld, 1998 pp. 191-202). The way of competing for resources is changing. The so far most important material resources are being replaced with non-material resources and above all with knowledge and technology (Venkataraman, 2004, pp. 153-167). The basic factors the characterise the knowledge-based economy are: high-tech industry, information society services, services saturated with knowledge and education.

Knowledge management is currently one of the most essential factors that determine the position of an enterprise in the market. It does not only involve skilful use of the available resources but also obtaining the synergy effect. In order to manage knowledge, the managerial staff must have at their disposal not only appropriate resources of knowledge but also a definite structure of management aided by IT (information technology) tools (Del Giudice \& Della Peruta, 2016, pp. 484-498).

The knowledge management system is responsible for providing the user with information that, after being processed, enables them to make efficient decisions (Cairó \& Tejeda-Hernández, 2010 p. 87). The role of the tools that process data and provide information necessary for this purpose is played by 
IT systems. Their function is to aid knowledge management in an organisation while the knowledge itself remains in the competence of people.

The objective of the paper was to present how the process of knowledge management in modern enterprises is aided by information technologies. The publication was financed with a grant from the Ministry for Higher Education for statutory activities.

\section{Literature review}

The tools supporting knowledge management fall into two groups, non-IT and IT ones. The non-IT resources include: Cross-functional project teams, KM training \& education, Storytelling, and Mentoring (Vaccaro et al., 2010, pp. 1076-1089). And the majority of the IT tools supporting knowledge management belong to one of the following categories (Bali et al., 2009):

- groupware systems \& KM 2.0;

- the intranet and extranet;

- data warehousing, data mining, \& OLAP;

- decision support systems;

- content management systems;

- document management systems;

- artificial intelligence tools;

- simulation tools;

- semantic networks.

Generally, it can be stated that they belong to the three basic groups: online tools, IT systems (computer applications), data resources together with relevant software managing access to them.

The universal access to the internet has meant that more and more users take advantage of the global network. The use of the internet is becoming increasingly intensive, which manifests itself in the fact that internet users spend a lot of time online and use diverse online applications. The notion of Web 2.0 refers to the more and more popular tools that enable two-way online communication. These tools, referred to as social, are blogs, wikis, internet fora, commenting, shared work areas, social portals and different sorts of instant messengers (Bebensee et al., 2010, pp. 22-41; Gurteen, 2012, pp. 5-13). The enormous popularity of the social networking sites (mainly Facebook) means that apart from the members of the community, these resources are also used by companies and institutions. These are not only tools for communicating with the customer but also a huge database that can be utilised e.g. for marketing purposes and other (Jimenez \& Barradas, 2010, pp. 273-301). The nomenclature originating from the 'Web 2.0' is transferred onto other notions related to the use of the online social resources. An example can be knowledge management - KM 2.0. As argued by Cronk (2012, pp. 74-87), the Web 2.0 tools 'facilitate the development of the social capital by sharing knowledge, which in turn increases the po- 
tential for creating the intellectual capital.' He defines social capital as the total resources existing in the social networks.

Integrated management-supporting IT systems include a whole range of software intended for companies and organisations. This software includes complex auxiliary systems that are in many cases even indispensable for the functioning of modern enterprises.

The data used in the tools supporting knowledge management are gathered in databases and data warehouses. Additionally, modern business software enables acquisition of information from outside, from the internet network, including social media. Data gathered in databases and warehouses have a definite structure, which facilitates the storage, retrieval and processing thereof. The huge quantity of data gathered in the present-day systems causes some difficulties but at the same time, it provides very extensive analytical options. Modern decision support systems can rapidly calculate indicators that managers need in order to manage the enterprise. Such a function is fulfilled by Business Intelligence (BI) systems. The OLAP cubes used in them enable accomplishment of three functions: querying and reporting (defining queries without having to use a database programming language), multidimensional analysis (the capability of conducting analyses from multiple perspectives) and statistical analysis (reducing the amount of data sent for analyses) (Techapichetvanich \& Datta, 2005, pp. 293-304).

It is obvious that Industry 4.0 would not be possible without the use of IT tools supporting knowledge management. Industry 4.0 is made up of: IoT Internet of Things and CPS (cyber-physical systems), support for a great number of data and advanced analyses (e.g. Big Data) as well as an appropriate communication infrastructure. This combination of technology, industry and digitalisation has created a new quality referred to as the fourth industrial revolution (Bahrin, et al., 2016, pp. 137-143).

\section{Methods}

In order to visualize the aiding of the process of knowledge management by information technologies, selected indicators characterizing the utilization of ICT (information and communication technologies) in various types of enterprises across the country were compiled. It was assumed that it is not just the availability of IT tools at the facilities concerned that matters but also the extent to which these tools are utilized.

The paper makes use of data published by Computerworld (2016), Gartner Group (2017a, 2017b), GUS (2015, 2016) (the Polish Central Statistical Office), Eurostat (2017), and World Bank (2017). The ICT utilization rates being analyzed were compiled for Polish enterprises divided according to the kind of activity and their size (small, medium, large). The domestic rates were compared with the values prevalent in the EU. 


\section{Results}

It should be mentioned that the analysis of knowledge management in enterprises cannot be performed in isolation from an analysis of the society within which the enterprise operates. That what sort of knowledge resources are available to an enterprise depends on the employees' education and experience. That how technologically advanced are the products or services that can be marketed depends not only on the customers' purchasing power but also on their level of knowledge. By way of example, IT companies will not be able to sell software if customers do not have enough computers and mobile devices. Also the way of reaching the audience can depend on the level of customers' knowledge, and consequently, on the tools used for gaining knowledge. It does not make any sense to start an online shop if the prospective customers do not use the internet.

The use of the internet is one of the indicators that allows determination of the way of acquiring information by people searching for it. Chart 1 presents the number of internet users per 100 people. Polish users were compared with users world-wide, in the European Union and in the Baltic countries. The dynamics of changes with regard to the use of the global network indicates that our country, despite being above the global average, significantly deviates from the average value for the member states of the European Union. This situation has not changed since the 1990s. The comparison with the neighboring countries does not look good, either. Among the neighbors, Poland only precedes Belarus and Ukraine while Germany, Czech Republic, Slovakia, Lithuania and Russia can all boast significantly higher rates. Even though the situation has improved in recent years (an increase from $75.8 \%$ in 2015 to $80.4 \%$ in 2016), our country still ranks as low as 23rd among the 29 analyzed ones with regard to access to broad-band internet.

Table 1 presents the use of ICT (information and communication technologies) in enterprises in Poland; the data concern the year 2016. The table 1. specifies selected kinds of activity; additionally, the companies have been divided into small (10 to 59 people), medium-sized (50 to 249 people) and large (250 people and more).

In total, $94.7 \%$ enterprises use computers and $93.8 \%$ have internet access. The best situation is in the large companies where $99.8 \%$ of the objects of study are computerized and 99.7 have internet access. Even though in our days it is hard to imagine an enterprise that does not use IT tools, among the small companies as many as $6.3 \%$ do not have a computer and $7.5 \%$ have no internet access. The most advanced companies (among those analyzed) pursue activities in the scope of finances and insurances.

The changes in technologies and the development of software have meant that mobile devices are more and more frequently used with business software and for remote access to the company's IT resources. The data presented show that also in this respect, it is above all the large companies that implement the innovative technologies. The use of IT technologies by employees shows that 
even though over $90 \%$ of companies have an IT infrastructure, a significant percentage of employees do not use it.

IT resources in enterprises mainly comprise integrated management systems. Table 2 summarizes the shares of companies using ERP (enterprise resource planning) and CRM (customer relationship management) systems in 2014 and 2015. The summary takes account for the division according to the size of the enterprise as well as for selected scopes of activity. Even though computer-aided management is very important in present times, merely every fifth enterprise has an ERP system at its disposal. The best situation is in large enterprises where these systems occur in $83.2 \%$, it is significantly worse in the small ones where only $14.2 \%$ have this system. It turns out that the CRM systems are much more popular among the small companies while in the large companies they are less popular then the ERP software. The struggle to gain customers turns out to be more of a priority for entrepreneurs operating on a smaller scale. Among the kinds of activity, best equipped with software for company management (both ERP and CRM) is the IT and communication industry. It can be stated that while large companies are already to a large extent computerized, implementation of business software is taking place with great intensity in the SME sector (small and medium-sized enterprises). Even though the global and domestic markets are dominated by large suppliers, like SAP, Microsoft or Oracle (according to Computerworld (2016) and Gartner Group (2017b)), the current situation also provides opportunities for smaller software producers, including domestic companies.

In the ranking of European Union states with regard to the ERP system utilization by enterprises, Poland ranked very low, with a score by 9 percentage points lower than the EU average.

The dynamic development of IT and communication technologies generates the need for improving ICT competencies among people employed in enterprises. In 2015, only 5.4\% of companies provided trainings for ICT specialists and $9.9 \%$ had trainings for other employees. The problem of the lack of trainings occurs in the small companies; in the large companies, such trainings were organized in $46.0 \%$ and $50.7 \%$ of them respectively.

Knowledge management in an enterprise does not only include acquisition of information but also making it available. In 2016, 91.8\% of large companies had a website of their own; the average for enterprises was $67 \%$. Irrespective of the size of the enterprise and the kind of activity, the basic function of a website is to present products, catalogues or pricelists, or the serviced offered by the enterprise.

More and more commonly, enterprises take advantage of social media in business as a new communication channel in order to promote their products and brands and to acquire information on prospective customers. Social marketing allows creating a group of loyal customers and quickly acquiring new ones. In the study year, $23.4 \%$ of enterprises used social networking sites, wherein $49.8 \%$ of large companies. Taking into consideration the territorial division 
of the country, the largest percentage of enterprises using social media was in the Mazowieckie province (35.3\%) and the smallest in the Świętokrzyskie province $(16.2 \%)$.

One of the modern IT technologies of our time is cloud computing. The cloud computing services were used by $8.2 \%$ of Polish enterprises. They gained the greatest popularity among companies employing at least 250 people (31.1\%) and those operating in the information and communication sector (33.7\%). In turn, the percentage of enterprises conducting so-called big data analyses was $5.9 \%$, wherein $17.6 \%$ of large companies. Due to the specificity of the activity, the highest share was noted in IT and communication section (17.2\%).

The importance that enterprise managers attach to IT tools is evidenced by the fact that over one third of enterprises incur expenditure on purchase of ICT equipment (IT and/or telecommunication). Among these entities, it is the large companies that dominate as they made purchases of ICT equipment more frequently than the small enterprises. More common were investments on purchases of computers and IT accessories than on telecommunication equipment.

It can be stated that the so far rapid development of modern IT tools will be continued. According to Gartner Group (2017a), the most prospective trends are: Artificial Intelligence and Advanced Machine Learning, Intelligent Apps, Intelligent Things, Virtual Reality and Augmented Reality, Digital Twins, Blockchains and Distributed Ledgers, Conversational Systems, Mesh App and Service Architecture, Digital Technology Platforms, Adaptive Security Architecture. These technologies are tools the vast majority of which are already and will be used in the further for knowledge management. This utilization will first take place in enterprises.

\section{Conclusion}

Within the utilization of the ICT technology, Poland achieves indicators that are significantly lower than the average for the European Union. The considerable diversity in the rate of utilization of IT technologies occurs in the individual groups of enterprises. The larger companies achieved a significantly higher rate of saturation with IT tools than the smaller facilities. By way of example, while the percentage of Polish enterprises having computers is $94.7 \%$, in the case of large companies it is $99.8 \%$. An even greater discrepancy concerns internet access. Also, a diversity between the individual provinces can be noticed. Implementation of modern IT and computer technologies (like e.g. computing clouds, big data, social media, e-commerce) allow effective knowledge management in enterprises. The indicators presented herein show that the managerial staff appreciate the importance of knowledge and invest in its development. 


\section{References}

Bahrin, M.A.K., Othman, M.F., Nor, N.H., \& Azli, M.F.T. (2016). Industry 4.0: A review on industrial automation and robotic. Jurnal Teknologi, 78(613). doi:10.11113/jt.v78.9285.

Bali, R., Wickramasinghe, N., \& Lehaney, B. (2009). Knowledge management primer. London: Routledge.

Bebensee, T., Helms, R., \& Spruit, M. (2012). Exploring Web 2.0 Applications as a means of Bolstering up Knowledge Management. In D. Gurteen (Ed.), Leading issues in social knowledge management. Reading: Academic Conferences Limited.

Cairó, O., \& Tejeda-Hernández, N. (2010). Application of IT tools in KMS within a social ecology. In Tsui, E. (Ed.), Proceedings of the 7th International Conference on Intellectual Capital, Knowledge Management and Organisational Learning. Hong Kong: Academic Conferences Limited.

Computerworld. (2016). Computerworld Top200. Retrieved 25.03.2017 fromhttps://www.computerworld.pl.

Cronk, M. (2012). Social capital, knowledge sharing, and intellectual capital in the Web 2.0 enabled world. In D. Gurteen (Ed.), Leading issues in social knowledge management. Reading: Academic Conferences Limited.

Del Giudice, M., \& Della Peruta, M.R. (2016). The impact of IT-based knowledge management systems on internal venturing and innovation: a structural equation modeling approach to corporate performance. Journal of Knowledge Management, 20(3). doi: 10.1108/JKM-07-2015-0257.

Eurostat. (2017). Database. Retrieved 25.03.2017 from http://ec.europa.eu/ eurostat.

Gartner Group. (2017a). Top 10 strategic technology trends for 2017. Retrieved 25.03.2017 from https://www.gartner.com.

Gartner Group. (2017b). Top strategic predictions for 2017 and beyond: surviving the storm winds of digital disruption. Retrieved 25.03.2017 from https: / www. gartner.com.

Gurteen, D. (1998). Knowledge, creativity and innovation. Journal of Knowledge Management, 2(1). doi:10.1108/13673279810800744.

GUS. (2015). Information society in Poland. Results of statistical surveys in the years 2011-2015. Retrieved 25.03.2017 from http://stat.gov.pl.

GUS. (2016). Information society in Poland. Results of statistical surveys in the years 2012-2016. Retrieved 25.03.2017 from http://stat.gov.pl.

Jimenez, G., \& Barradas, C. (2010). Knowledge management system based on Web 2.0 technologies. In: Yao, J. (Ed.), Web-based support systems. Advanced information and knowledge processing. London: Springer. doi:10.1007/978-1-84882-628-1_13.

Loshin, D. (2001). EnterpriseKnowledge Management. The dataqualityapproach. San Fransisco: Morgan Kaufmann. doi:10.1016/b978-012455840-3/50001-7. 
Siesfeld, G.A. (1998). Introduction. In D. Neef, G.A. Siesfeld, \& J. Cefola (Eds.), The economic impact of knowledge. Butterworth-Heinemann, Boston: Taylor \& Francis. doi:10.1016/B978-0-7506-7009-8.50017-3.

Techapichetvanich, K., \& Datta, A. (2005). Interactive Visualization for OLAP. In: O. Gervasi, M.L. Gavrilova, V. Kumar, A. Laganà, H.P. Lee, Y. Mun, D. Taniar, C.J.K. Tan (Eds.), Computational Science and Its Applications - ICCSA 2005. Berlin: Springer. doi:10.1007/11424857_23.

Vaccaro, A., Parente, R., \& Veloso, F. M. (2010). Knowledge management tools, inter-organizational relationships, innovation and firm performance. Technological Forecasting and Social Change, 77(7). doi:10.1016/j. techfore.2010.02.006.

Venkataraman, S. (2004). Regional transformation through technological entrepreneurship. Journal of Business Venturing, 19(1). doi:10.1016/j. jbusvent.2003.04.001.

World Bank. (2017). Retrieved 25.03.2017 from http://data.worldbank.org.

\section{Acknowledgements}

Author contributions: authors have given an approval to the final version of the article. Authors contributed to this work equally.

Funding: this research was fully funded by the University of Agriculture in Krakow, Faculty of Production and Power Engineering statutory sources. Publication was financed with a grant from the Ministry for Higher Education for statutory activities.

Note: the results of this study were presented at 9th International Conference on Applied Economics Contemporary Issues in Economy (June 22-23, Torun, Poland). 


\section{Appendix}

Table 1.

Use of ICT in enterprises in Poland in 2016 (in \%)

\begin{tabular}{|c|c|c|c|c|c|c|c|}
\hline \multirow[b]{2}{*}{ Specification } & \multicolumn{4}{|c|}{ Enterprises } & \multicolumn{3}{|c|}{ Employees } \\
\hline & $\begin{array}{l}\text { using } \\
\text { computers }\end{array}$ & $\begin{array}{c}\text { with } \\
\text { internet } \\
\text { access }\end{array}$ & $\begin{array}{c}\text { providing } \\
\text { employees } \\
\text { with } \\
\text { mobile } \\
\text { devices }\end{array}$ & $\begin{array}{l}\text { providing } \\
\text { employ- } \\
\text { ees with } \\
\text { remote } \\
\text { access } \\
\text { to the } \\
\text { company's } \\
\text { resources }\end{array}$ & $\begin{array}{c}\text { using } \\
\text { computers } \\
\text { for } \\
\text { business } \\
\text { purposes }\end{array}$ & $\begin{array}{c}\text { using } \\
\text { computers } \\
\text { with } \\
\text { internet } \\
\text { access for } \\
\text { business } \\
\text { purposes }\end{array}$ & $\begin{array}{l}\text { equipped } \\
\text { with } \\
\text { mobile } \\
\text { devices }\end{array}$ \\
\hline manufacturing & 95.1 & 94.1 & 63.1 & 76.0 & 33.5 & 28.3 & 12.7 \\
\hline construction & 91.5 & 90.2 & 66.6 & 75.9 & 30.9 & 29.7 & 17.2 \\
\hline trade; repair & 95.1 & 93.9 & 64.0 & 77.2 & 54.6 & 45.3 & 20.8 \\
\hline $\begin{array}{l}\text { transportation and } \\
\text { storage }\end{array}$ & 94.9 & 94.3 & 67.3 & 80.1 & 44.1 & 41.7 & 15.4 \\
\hline $\begin{array}{l}\text { information and com- } \\
\text { munication }\end{array}$ & 99.3 & 99.0 & 89.1 & 94.5 & 96.0 & 94.8 & 63.1 \\
\hline $\begin{array}{l}\text { financial and insurance } \\
\text { activities }\end{array}$ & 99.8 & 99.8 & 68.1 & 84.4 & 94.1 & 88.7 & 43.4 \\
\hline science and technology & 98.3 & 97.8 & 71.9 & 84.1 & 88.3 & 86.4 & 43.3 \\
\hline ICT sector & 99.3 & 99.0 & 86.1 & 93.8 & 89.1 & 86.4 & 56.8 \\
\hline total & 94.7 & 93.8 & 65.3 & 77.7 & 46.0 & 41.1 & 19.6 \\
\hline small & 93.7 & 92.5 & 61.0 & 74.3 & 39.2 & 36.3 & 17.8 \\
\hline medium & 99.0 & 98.8 & 80.8 & 90.7 & 40.3 & 37.4 & 17.1 \\
\hline
\end{tabular}

Source: Own preparation based on GUS (2016).

Table 2.

ERP and CRM systems in enterprises in Poland in 2014 and 2015 (in \%)

\begin{tabular}{lrrrr}
\hline \multirow{2}{*}{ Specification } & \multicolumn{3}{c}{ Enterprises using system } \\
\cline { 2 - 5 } & \multicolumn{2}{c}{ ERP } & 2014 & CRM \\
\cline { 2 - 5 } & 2014 & 2015 & 2015 \\
\hline manufacturing & 25.2 & 24.7 & 9.6 & 24.2 \\
construction & 10.8 & 10.0 & 26.4 & 28.2 \\
trade; repair & 24.1 & 22.6 & 18.7 & 19.1 \\
transportation and storage & 18.0 & 13.6 & 57.2 & 58.1 \\
information and communication & 45.5 & 40.9 & 55.0 & 55.9 \\
financial and insurance activities & 28.0 & 28.7 & 21.8 & 24.4 \\
\hline total & 22.0 & 20.9 & 17.6 & 19.9 \\
small & 15.3 & 14.2 & 37.7 & 42.2 \\
medium & 48.9 & 46.5 & 62.7 & 65.2 \\
large & 82.2 & 83.2 & & 2 \\
\hline
\end{tabular}

Source: Own preparation based on GUS (2015). 


\section{Chart 1.}

Internet users in years 1995-2015 (per 100 people)

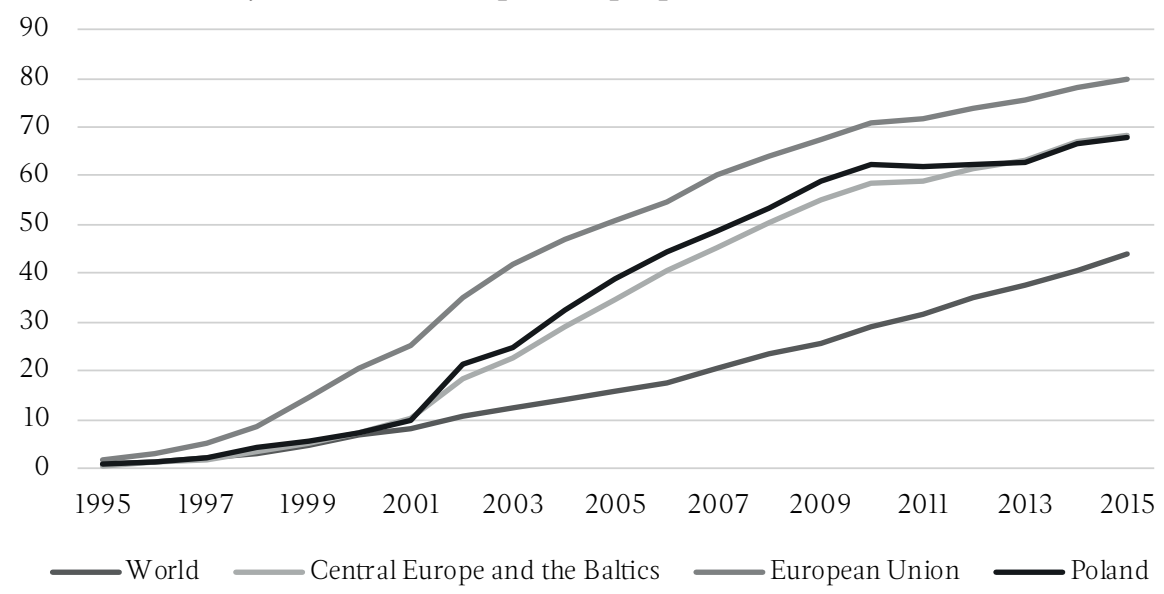

Source: Own preparation based on World Bank (2017). 
